\title{
Study on MHD Flow over a Stretching Surface with Convective Boundary Condition by Numerical Method
}

\author{
Uma Munivenkatappa ${ }^{1}$ (D), Sushma Shankar ${ }^{1}$ (D), Veena Bengaluru Nagendra ${ }^{1, *}$ (D) Nancy Samuel ${ }^{1}$ (i) \\ 1 Department of Mathematics, M. S. Ramaiah Institute of Technology, Bengaluru, India (Affiliated to VTU) \\ * Correspondence: mvymath@gmail.com (V.B.N);
}

Scopus Author ID 57202830024

Received: 9.08.2021; Revised: 15.10.2021; Accepted: 19.10.2021; Published: 18.11.2021

Abstract: The thermal and mass diffusive MHD flow through a stretching sheet has been inspected in the presence of a chemically reactive solute under convective boundary conditions in the present paper. The non-linear PDEs of the system concerning the flow, temperature, and species are recasted into a set of non-linear ODEs using ST. The consequential system of the differential equations is numerically resolved by using an implicit FDS in combination with the QL technique. The velocity ratio factor plays an important role in reducing the thickness of the velocity boundary layer, whereas the presence of magnetic parameters decreases the thickness of the velocity boundary layer profile. The study reveals that the fluid moves away from the surface during injection, resulting in a fall of the velocity gradient, whereas the opposite effect is observed in suction. The thermal and concentration boundary layer thicknesses are influenced by non-dimensional numbers, namely Prandtl and Schmidt numbers. The reaction rate parameter acts as a decelerating agent, and it thins the solute boundary layer formed in the neighborhood of the sheet. An increase in the convective parameter leads to an increase in the plate surface temperature. The present results of the paper are compared with the existing one, and good agreement is found between them.

Keywords: horizontal plate; boundary layer; suction/injection; first-order chemical reaction; magnetic force; QL technique.

(C) 2021 by the authors. This article is an open-access article distributed under the terms and conditions of the Creative Commons Attribution (CC BY) license (https://creativecommons.org/licenses/by/4.0/).

\section{Nomenclature:}

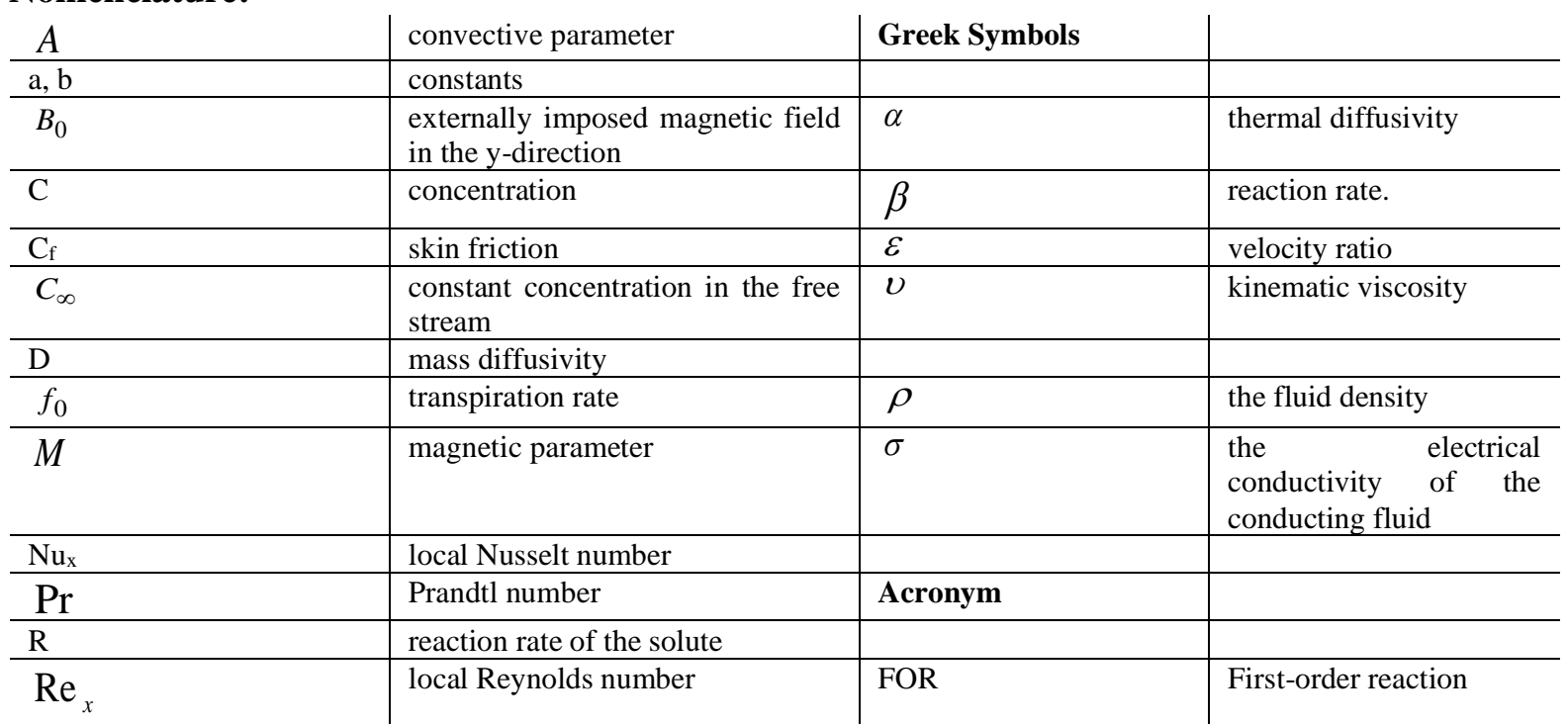




\begin{tabular}{l|l|l|l}
\hline$S c$ & Schmidt number & FDS & Finite-difference scheme \\
\hline $\mathrm{Sh}_{\mathrm{x}}$ & local Sherwood number. & ODE & $\begin{array}{l}\text { Ordinary differential } \\
\text { equation }\end{array}$ \\
\hline $\mathrm{T}$ & $\begin{array}{l}\text { fluid temperature in the boundary } \\
\text { layer }\end{array}$ & PDE & $\begin{array}{l}\text { Partial differential } \\
\text { equation }\end{array}$ \\
\hline $\mathrm{u}$ & $\begin{array}{l}\text { velocity component along } \mathrm{x} \\
\text { direction }\end{array}$ & QL & Quasi-linearization \\
\hline $\mathrm{v}$ & $\begin{array}{l}\text { velocity component along y } \\
\text { direction }\end{array}$ & ST & $\begin{array}{l}\text { similarity } \\
\text { transformation. }\end{array}$
\end{tabular}

\section{Introduction}

The study of flow and heat transfer due to stretching surfaces has numerous industrial and engineering applications due to which it has been an important topic in the area of researchers for the past four decades; a few of its enormous applications are the extrusion of plastic sheets, wire drawing, paper production, polymer industries, the metal-working processes in metallurgy so on. Recently, Subhashini et al. [1], Vajravelu et al. [2], and Nandy et al. [3] have studied the characteristics of flow past a stretching sheet by considering various situations such as permeable surface, nanofluids, viscoelastic fluids, etc. Pop and $\mathrm{Na}$ [4] have considered the effect of the magnetic field to analyze the boundary layer flow over a permeable stretching sheet. Identically Kumaran et al. [5,6] have performed a study; due to an imposed magnetic field over a viscous flow past a stretching sheet, where the transition effect of boundary layer flow both under steady and unsteady is considered. Ibrahim and Shankar [7] have performed a numerical study on the boundary layer flow and heat transfer over a permeable stretching sheet in the presence of nanofluid with the effects of the magnetic field, slip boundary condition, and thermal radiation.

Naramgari and Sulochana [8] have made a similar study on the flow in the liquids added with nanoparticles in the presence of the magnetic field. Afify [9] numerically investigated the effect of chemical reaction and mass transfer of MHD convective flow through a stretching sheet. Kechil and Hashim [10] studied the fluid flow through stretching, which is not linear, by incorporating the effects of magnetic field and chemical reaction by using the series solution.

Aziz [11] made an analysis in the laminar boundary layer through a flat plate with convectional boundary conditions using ST.

Ishak [12] numerically investigated flow in a steady laminar boundary layer over a permeable flat plate in a uniform free stream where partial differential equations are converted to ordinary differential equations.

In this regard, many of the authors have dedicated their work to the flow-through laminar thermal boundary, such as Salleh et al. [13], Subhashini et al. [14], Mohamed et al. [15], Gorsan et al. [16], Chand et al. [17], and Mansur [18].

Roy and Anil Kumar [19] have obtained semi-similar solutions numerically of unsteady mixed convection in a rotating viscous fluid with varying time in the presence of prescribed wall temperature and heat flux conditions. They have incorporated an implicit finite difference scheme with a quasi-linearization technique.

Siddheshwar et al. [20] have considered thermophysical properties of twenty nanoliquids in their numerical study of the flow of a Newtonian nanoliquid due to a curved stretching sheet.

Mallikarjuna et al. [21] have performed a numerical study and modeled a mathematical model for Darcy-Forchheimer flow for two-phase dusty hybrid nanofluid over a stretching sheet. Rajput et al. [22] used suitable ST to transform PDEs to non-linear ODEs to study thermal 
buoyancy induced in boundary layer flow. Gajjela and Nandkeolyar [23] have used standard spectral QL methodology in the presence of a magnetic field to investigate the flow and heat transfer phenomena in MHD over a linearly stretching sheet. Megahed et al. [24] have considered a problem in boundary layer laminar flow for MHD fluid with heat flux and solved the coupled non-linear ODE with an effective shooting method coupled with the Runge-Kutta algorithm. Shoaib et al. [25] employ a computing-based Lobatto IIIA method to study heat and mass transfer in 3-D MHD flow over an extending sheet in nanofluids. Walelign et al. [26] have obtained results by analytical method to study heat and mass transfer 2-D unsteady flow of Williamson fluid under the presence of external effects near a permeable stretching sheet. Muthukumaran and Bathrinathan [27] have studied mixed convection flows of an incompressible viscous fluid towards a vertical stretching sheet by formulating variational principal. Qasim et al. [28] have performed a numerical study using Matlab built-in function bvp5c tool and analytical analysis using homotopy method in a mixed convection flow over a stretching sheet. Ghatani et al. [29] have obtained analytical expressions for velocity and temperature field using the singular perturbation method to study flow in thin Casson-nanofluid in stretching sheet with both injection and suction.

Some of the recent studies in the literature in streching sheet in the presence and absence of nanofluid and porous medium are available (Mahabaleshwar et al. [30], Kumar [31], Naganthran et al. [32], Ilyas et al. [33], Khan and Nadeem [34], Bognár, G. Hriczó [35], Das et al. [36]).

In the present paper, the authors have concentrated on studying the following objective:

To examine the properties of thermal and mass diffusion on an MHD flow through a permeable stretching sheet with the occurrence of convective boundary conditions and chemical reactions.

The non-linear PDEs of the system concerning the flow, temperature, and species are converted into a set of non-linear ODEs using ST.

The consequential system of the differential equation is solved numerically with the help of the implicit FDS with QL technique.

\section{Materials and methods}

\subsection{Mathematical formulation.}

A steady 2-D MHD boundary layer flow of an electrically conducting temperature fluid $T_{\infty}$ with chemically reactive species undergoing the FOR along a permeable stretching horizontal surface is considered. The plate and plane $y=0$ coincide; the flow is confined to the region $\mathrm{y}>0$. The velocity from an external source is considered as $U_{e}(x)=b x$ and the stretching velocity is assumed to be of the form $U_{w}(x)=a x$, where $\mathrm{a}>0$ and $\mathrm{b} \geq 0$. The temperature of the lower surface of the plate is Tf with a corresponding heat transfer coefficient hf. Let the strength of the magnetic field be ${ }^{B_{0}}$, which is applied transversely along the y-axis. The magnetic field generated by the motion of electrically conducting fluid and pressure gradient is neglected. In view of the above assumptions, the governing equations take the following form:

$$
\begin{aligned}
& \frac{\partial u}{\partial x}+\frac{\partial v}{\partial y}=0, \\
& u \frac{\partial u}{\partial x}+v \frac{\partial u}{\partial y}=U_{e} \frac{d U_{e}}{d x}+v \frac{\partial^{2} u}{\partial y^{2}}-\frac{\sigma B_{0}^{2}}{\rho}\left(u-U_{e}\right),
\end{aligned}
$$




$$
\begin{aligned}
& u \frac{\partial T}{\partial x}+v \frac{\partial T}{\partial y}=\alpha \frac{\partial^{2} T}{\partial y^{2}}, \\
& u \frac{\partial C}{\partial x}+v \frac{\partial C}{\partial y}=D \frac{\partial^{2} C}{\partial y^{2}}-R\left(C-C_{\infty}\right) .
\end{aligned}
$$

The relevant boundary conditions are

$$
\begin{aligned}
& u=U_{w}(x), v=V_{w},-k \frac{\partial T}{\partial y}=h_{f}\left(T_{f}-T_{w}\right), C=C_{w} \quad \text { at } \quad y=0, \\
& u \rightarrow U_{e}(x), T \rightarrow T_{\infty}, C \rightarrow C_{\infty} \quad \text { as } \quad y \rightarrow \infty,
\end{aligned}
$$

where $V_{w}<0$ represents suction velocity and $V_{w}>0$ represents injection velocity. The similar transformations considered are

$$
\begin{aligned}
& \psi=x \sqrt{a v} f(\eta), \theta(\eta)=\frac{T-T_{\infty}}{T_{f}-T_{\infty}}, \phi(\eta)=\frac{C-C_{\infty}}{C_{w}-C_{\infty}}, \quad \eta=y \sqrt{\frac{a}{v}}, \\
& u=\frac{\partial \psi}{\partial y}, v=-\frac{\partial \psi}{\partial x},
\end{aligned}
$$

On applying Eq. (6) continuity equation is satisfied, and hence the velocity components $u$ and $v$ are taken to be

$$
u=a x f^{\prime}(\eta), \quad v=-\sqrt{a v} f(\eta),
$$

where primes represent differentiation concerning $\eta$. On substituting the new variables in Eq. (7), with $f^{\prime}=F$, Eqs. (2) - (4) becomes a set of ODEs which are given below

$$
\begin{aligned}
& F^{\prime \prime}+f F^{\prime}-F^{2}+M(\varepsilon-F)+\varepsilon^{2}=0, \\
& \theta^{\prime \prime}+\operatorname{Pr} f \theta^{\prime}=0, \\
& \phi^{\prime \prime}+S c f \phi^{\prime}-S c \beta \phi=0,
\end{aligned}
$$

where $M=\sigma B_{0}^{2} / \rho a, \varepsilon=b / a, \operatorname{Pr}=v / \alpha, S c=v / D$ and $\beta=R / a$.

$V_{w}$ is taken as $V_{w}=-\sqrt{a v} f_{0}$, where $f_{0}>0$ for suction, $f_{0}<0$ for injection, and $f_{0}=0$ an impermeable surface. After the transformation boundary conditions, Eq. (5) reduces to

$$
\begin{array}{ll}
f(\eta)=f_{0}, & f^{\prime}(\eta)=1, \quad \theta^{\prime}(\eta)=-A[1-\theta(\eta)], \quad \phi(\eta)=1 \quad \text { at } \quad \eta=0, \\
f^{\prime}(\eta)=\varepsilon, & \theta(\eta)=0, \quad \phi(\eta)=0, \quad \text { at } \eta=\eta_{\infty},
\end{array}
$$

where $A=h_{f} / k(v / a)^{1 / 2}$ is the convective parameter.

$$
C_{f}=\frac{\mu\left(\frac{\partial u}{\partial y}\right)_{y=0}}{\rho U_{w}^{2}}, N u_{x}=\frac{-x k\left(\frac{\partial T}{\partial y}\right)_{y=0}}{k\left(T_{f}-T_{\infty}\right)}, S h_{x}=\frac{-x D\left(\frac{\partial C}{\partial y}\right)_{y=0}}{D\left(C_{w}-C_{\infty}\right)} .
$$

Using Eq. (6), the Eq. (12) becomes

$$
\begin{aligned}
& \left(\operatorname{Re}_{x}^{1 / 2}\right) C_{f}=F^{\prime}(0), \quad\left(\operatorname{Re}_{x}^{-1 / 2}\right) N u_{x}=-\theta^{\prime}(0),\left(\operatorname{Re}_{x}^{-1 / 2}\right) S h_{x}=-\phi^{\prime}(0), \\
& \text { where } \operatorname{Re}_{x}=U_{w}(x) x / v .
\end{aligned}
$$




\section{Results and Discussion}

Non-linear ODE's in Eqs. (8) - (10) in accordance with the boundary conditions are specified in Eq. (11) and are evaluated numerically by incorporating an implicit FDS adapting the QL method. Equations (8) - (10) are approximated by a sequence of linear equations to get quadratic convergence, and monotonicity following procedure is adopted as per Roy [19]. In order to reduce the error in the convergence of the solution obtained from numerical approximation in comparison to the exact solution, we have maintained the width as 0.005 . Up to four decimal places, the obtained results are free from step size. The convergence is achieved when the difference between the existing and earlier values of some parameters like $F^{\prime}(\eta), \theta^{\prime}(\eta)$ and $\phi^{\prime}(\eta)$ approaches to $10^{-4}$. To see the deviation, the present work is compared with the work carried by Aziz [11] and Subhashini [14], and a good agreement is found between both. The values are tabulated in the following Table 1.

Table 1. Computed values of $-\theta^{\prime}(0)$ for different values of $\operatorname{Pr}$ and $A$ when $M=0$.

\begin{tabular}{c|c|c|c|c|c|c} 
& \multicolumn{2}{|c|}{ Aziz [11] } & \multicolumn{2}{c|}{ Subhashini [14] } & \multicolumn{2}{c}{ Present result } \\
\hline$A$ & $\operatorname{Pr}=0.72$ & $\operatorname{Pr}=10$ & $\operatorname{Pr}=0.72$ & $\operatorname{Pr}=10$ & $\operatorname{Pr}=0.72$ & $\operatorname{Pr}=10$ \\
\hline 0.8 & 0.2159 & 0.3812 & 0.21586 & 0.38119 & 0.2159 & 0.3811 \\
\hline 1.0 & 0.2282 & 0.4213 & 0.22818 & 0.42134 & 0.2282 & 0.4212 \\
\hline 5.0 & 0.2791 & 0.6356 & 0.27913 & 0.63557 & 0.2791 & 0.6356 \\
\hline 10 & 0.2871 & 0.6787 & 0.28715 & 0.70255 & 0.2871 & 0.6787
\end{tabular}

Computations are carried out for several values of $\operatorname{Pr}$, which lies between 0.7 and 7.0, $f_{w}\left(-0.5 \leq f_{w} \leq 0.5\right), A(0.2 \leq A \leq 20), \varepsilon(0 \leq \varepsilon \leq 2), M(0 \leq M \leq 3), \beta(0 \leq \beta \leq 2), S c(0.22 \leq S c \leq 2.57)$. The boundary layer edge is considered around 8 and 15, depending on the value of the parameters.

Figure 1(a) is a plot where the effect of the suction/injection parameter $f_{w}$ on the velocity profile $(F(\eta))$ for various values of the velocity ratio parameter is drawn. It is observed that the boundary layer structure exists for the flow and the thickness of the boundary layer reduces with the rise $\varepsilon$. It may be noted that there exists a fixed value $a$ and $\mathrm{b}$ such that the ratio $\varepsilon=b / a$ increases (i.e. $\varepsilon>1$ ) corresponding to the stretching of the surface. This requires an increment in the straining motion, which leads to an increase in acceleration of the external stream, which in turn affects the thinning of the boundary layer. Further, it is seen from the same figure that $\varepsilon<1$ there exists an inverted boundary layer structure for the flow. This is due to the fact that $\varepsilon<1$ the stretching velocity $a x$ of the surface exceeds the velocity $b x$ of the external stream. Whereas, the boundary layer thickness of both thermal and concentration boundary layer decreases with the increase in velocity ratio parameter, which is clear from Figure 1(b). It is noticeable that the boundary layer thickness of the concentration profile is approximately 6.7 for $\varepsilon=0.5$, whereas $\eta_{\infty} \approx 5.2$ for $\varepsilon=1.5$. It may be noted from Figure 1(a) that during injection, $\left(f_{w}=-0.5\right)$ the reduction in the velocity gradient is noted as the fluid is carried away from trying to maintain the same velocity over a small region near the surface; this effect is reversed in case of suction $\left(f_{w}=0.5\right)$. The behavior of the temperature profile $(\theta(\eta))$ concerning injection $\left(f_{w}=-0.3\right)$ and suction $\left(f_{w}=0.3\right)$ is plotted in Figure 1(c). It is noticed that there is an increase in the thermal boundary layer thickness during the injection. To support the former statement, it is noted that the thermal boundary layer thickness is approximately 4.5, whereas the thermal boundary layer thickness $f_{w}=0.3$ for a fixed value of Prandtl number ( $\operatorname{Pr}=0.7$ ). In addition, from the same Figure 1(c), the effect of the Prandtl number on the temperature profile is also observed and noted that the thermal boundary layer thickness decreases sharply with an increase in Pr and 
hence induces an increase in the surface temperature gradient. Quantitatively , the thermal boundary layer thickness is approximately 4.5, whereas the thermal boundary layer thickness $\quad \operatorname{Pr}=7.0$ for a fixed value of $f_{w}=-0.3$. Higher the Prandtl number (water), the thermal conductivity is reduced, resulting in decreased thermal boundary layer thickness.

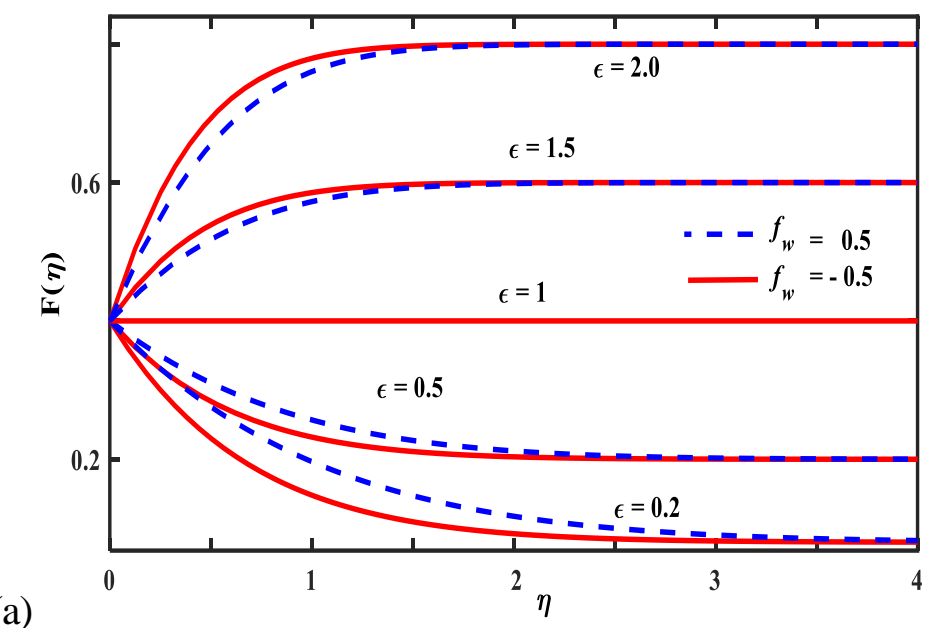

(a)

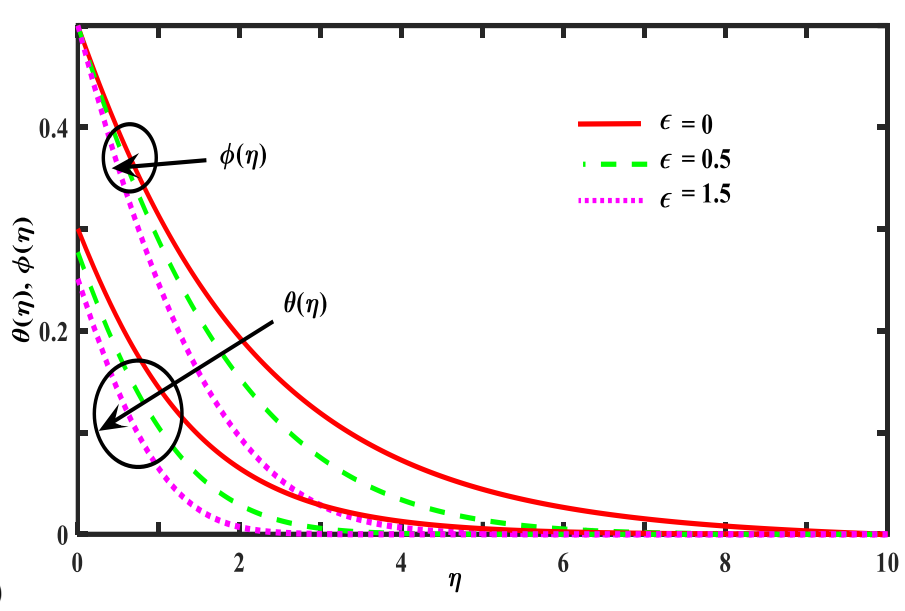

(b)

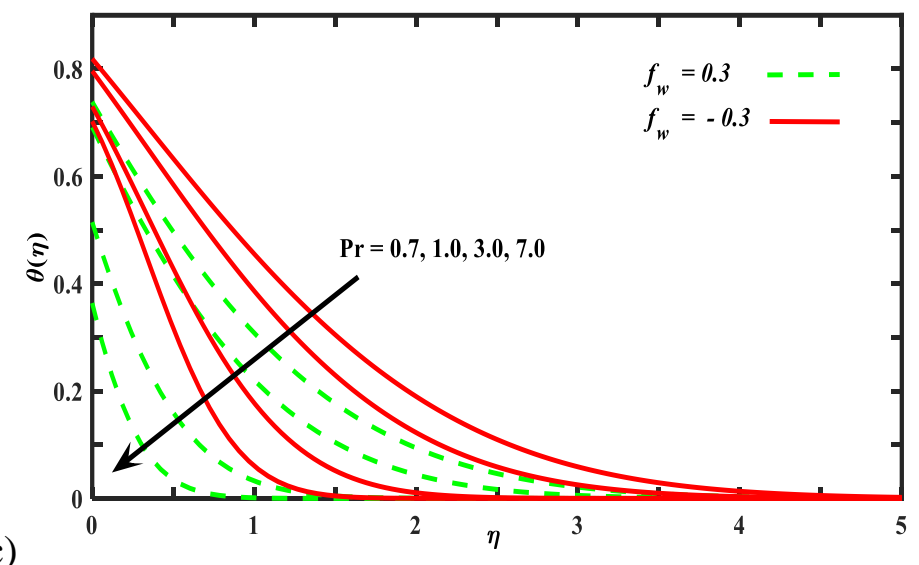

Figure 1. (a) Plot showing the effect of $\varepsilon$ and $f_{w}$ on velocity profile for $\operatorname{Pr}=0.7, S c=0.94, A=1.0$, $M=0.1$ and $\beta=0.5$; (b) Plot showing the effect of $\varepsilon$ on temperature $(\theta(\eta))$ and concentration $(\phi(\eta))$ profiles for $\operatorname{Pr}=0.7, S c=0.22, A=1.0, M=0.1, f_{w}=0.5$ and $\beta=0.5$; (c) Plot showing the effect of $\operatorname{Pr}$ and $f_{w}$ on temperature profile $(\theta(\eta))$ for $\varepsilon=0.5, S c=0.94, A=1.0, M=0.1$ and $\beta=0.5$ 
The effect of Schmidt number $(S c)$ and reaction rate parameter $(\beta)$ on concentration profile is plotted in Figure 2(a). The non-dimensional Schmidt number (Sc) characterizes the fluid flow, which in turn increases with the decrease in molecular diffusivity $(D)$. It is also observed that the effect of $S c$ is to reduce the thickness of the concentration boundary layer, i.e., when reaction rate parameter, $\beta=0$, the concentration boundary layer thickness reduces from $\eta_{\infty} \approx 6.7$ to $\eta_{\infty} \approx 3.2$ and $S c$ increases from $S c=0.22$ to $S c=0.94$. Also, the curves denoting the concentration distribution confirm concentration boundary layer thickness decreases with an increase in reaction rate parameter $(\beta)$. In the case of distribution of reactive solute, the constant reaction rate serves as a decelerating agent leading to thinner of the solute boundary layer formed in the neighborhood of the sheet which is depicted in Figure 2 (b). The concentration gradient increases with an increase $\beta$ because of the decrease in boundary layer thickness. Also, the effect $S c$ is more pronounced for suction $f_{w}=0.5$ compared to injection $f_{w}=-0.5$. In particular, $f_{w}=-0.5$, approximately $14 \%$ increment in mass transfer at the wall is observed as $S c$ increases from 0.94 to 2.57, whereas approximately $90 \%$ increment is observed for $f_{w}=0.5$ when $\varepsilon=0$, and $\beta=0.5$.

Figure 2(c) is a plot showing the effect of convective parameter, $A$ for a fixed of values of $\operatorname{Pr}=0.7, S c=0.94, f_{w}=-0.1, \beta=0.5, m=0.1$ and $\varepsilon=0.3$. The results presented in this figure reveal that there is an increase in the plate surface temperature with the increase in $A$. As $A \rightarrow \infty$ the solution approaches to the classical solution for the constant surface temperature, which indeed can be proved from the boundary condition in Eq. (11), i.e., $\theta(0)=1$ as $A \rightarrow \infty$.

Figure 2(d) is a plot the effect of magnetic parameter, $M$ on the velocity profile for fixed values of $f_{w}=0.5, \varepsilon=0, \beta=0.5, \operatorname{Pr}=0.7, S c=0.22$ and $A=1.0$. The magnetic force opposes the fluid motion as the presence of a magnetic field leads to an increase in mass transfer characterized by Lorentz force. Therefore, the velocity boundary layer thickness decreases with an increase in $M$.

(a)

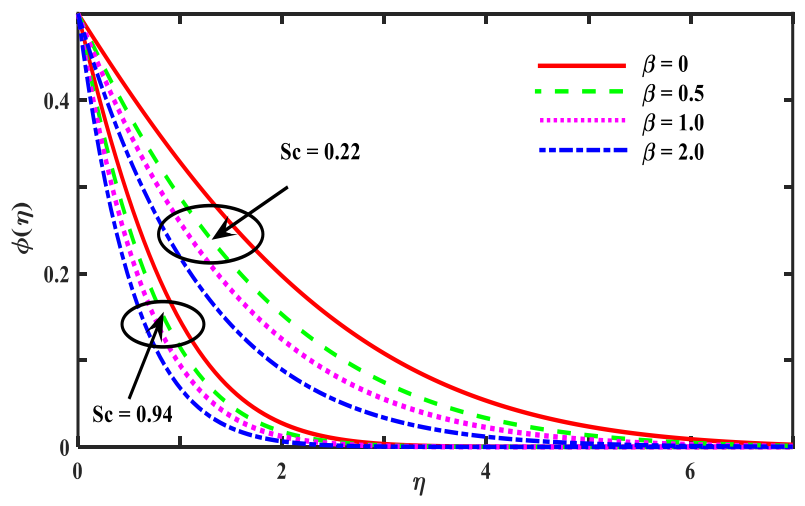

(b)

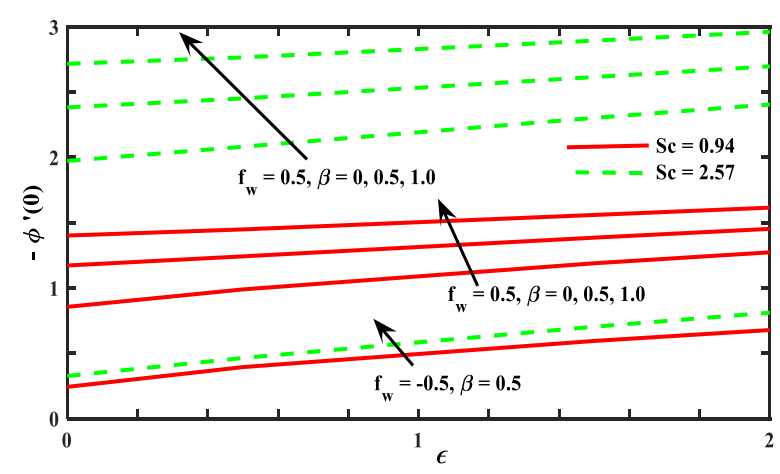


(c)

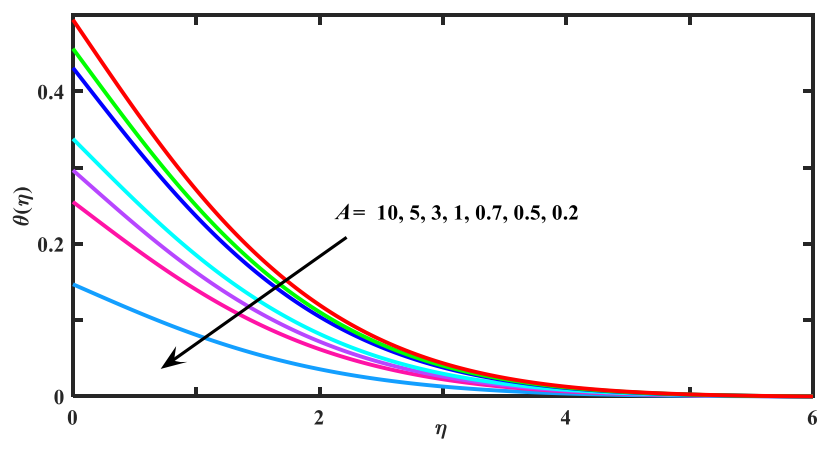

(d)

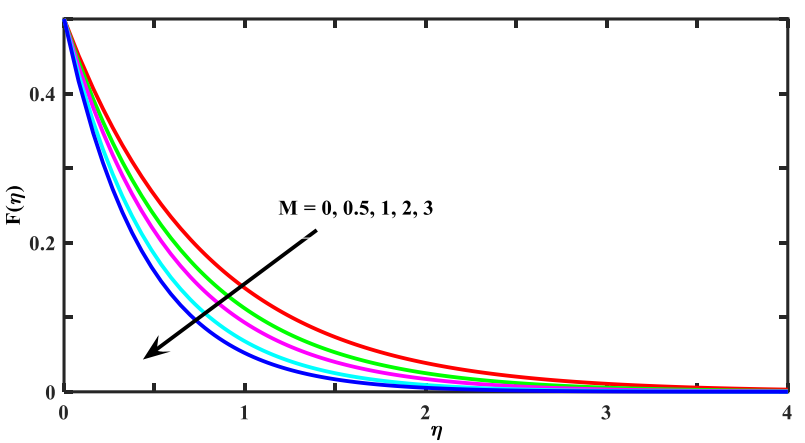

Figure 2. (a) Plot showing the effect of $S c$ and $\beta$ on concentration profile $(\phi(\eta))$ for $\varepsilon=0.5, \operatorname{Pr}=0.7$, $A=1.0, M=0.1$ and $f_{w}=0.5$; (b) Plot showing the variations of $-\phi^{\prime}(0)$ with $\varepsilon$ for various values of $f_{w}$, $\beta$ and $S c$ when $\operatorname{Pr}=0.7 A=1.0$ and $M=0.1$; (c) Plot showing the effect of $A$ on temperature profile $(\theta(\eta))$ for $\varepsilon=0.3, S c=0.94, \operatorname{Pr}=0.7$ and $f_{w}=-0.1, M=0.1$ and $\beta=0.5$; (d) Plot showing the effect of $M$ on velocity profile for $\operatorname{Pr}=0.7, S c=0.22, A=1.0, \varepsilon=0, f_{w}=0.5$ and $\beta=0.5$.

\section{Conclusions}

The influence of chemically reactive species on an MHD boundary layer flow of an electrically conducting fluid past a stretching permeable flat plate with convective boundary condition is analyzed numerically, and the following conclusions are drawn:

A Higher Prandtl number leads to a significant reduction in temperature boundary layer thickness $(\theta(\eta))$. It is noticed that the thickness reduces approximately by $95 \%$ with the rise in $\operatorname{Pr}$ from $\operatorname{Pr}=0.7$ to $\operatorname{Pr}=3.0$; as a result, heat transfer at the wall $\left(-\theta^{\prime}(0)\right)$ increases. A similar effect is observed for a higher $S c$ in concentration boundary layer thickness $(\phi(\eta))$.

Approximately $36 \%$ reduction in the concentration boundary layer thickness is observed as the reaction rate parameter $\beta$ rises from 0.5 to 2.0. The effect of mass transfer at the wall for different values $\beta$ is more felt for the higher value of Schmidt number. $(S c=2.57)$

The rise in plate surface temperature is noted with the rise of the convective parameter (A). The effect of the Prandtl number on heat transfer at the wall increases with an increase in value $(A)$.

The thickness of the boundary layer decreases with an increase in $\varepsilon$ for $\varepsilon>1$. Whereas, $\varepsilon<1$, the boundary layer thickness increases with the decrease of the value of $\varepsilon$. Also, the presence of $M$ decreases the boundary layer thickness of the velocity profile. 


\section{Funding}

This research received no external funding.

\section{Acknowledgments}

All authors thank the institute for its support in carrying out research.

\section{Conflicts of Interest}

The authors declare no conflict of interest.

\section{References}

1. Subhashini, S. V.; Sumathi, R.; Pop, I. Dual solutions in a double-diffusive convection near stagnation point region over a stretching vertical surface. Int. J. Heat Mass Trans. 2012, 55, 2524-2530, https://doi.org/10.1016/j.ijheatmasstransfer.2012.01.008.

2. Vajravelu, K.; Prasad, K. V.; Chiu-On, N. Unsteady convective boundary layer flow of a viscous fluid at a vertical surface with variable fluid properties. Nonlinear Anal. Real World Appl. 2013, 14, 455-464, https://doi.org/10.1016/j.nonrwa.2012.07.008.

3. Nandy, S. K.; Sidui, S.; Mahapatra, T. R. Unsteady MHD boundary-layer flow and heat transfer of nanofluid over a permeable shrinking sheet in the presence of thermal radiation. Alexandria Eng. J. 2014, 53, 929-937, https://doi.org/10.1016/j.aej.2014.09.001.

4. Pop, I.; Na, T. Y. A note on MHD flow over a stretching permeable surface. Mech. Res. Commun. 1998, 25, 263-269. https://doi.org/10.1016/S0093-6413(98)00037-8.

5. Kumaran, V.; Kumar, A. V.; Pop, I. Transition of MHD boundary layer flow past a stretching sheet. Commun. Nonlinear Sci. Numer. Simulat. 2010, 15, 300-311, https://doi.org/10.1016/j.cnsns.2009.03.027.

6. Kumaran, V.; Banrejee, A. K.; Kumar, A. V.; Pop, I. Unsteady MHD flow and heat transfer with viscous dissipation past a stretching sheet. Int. Commun. in Heat Mass Transfer 2011, 38, 335-339, https://doi.org/10.1016/j.icheatmasstransfer.2010.11.011.

7. Ibrahim, W.; Shankar, B. MHD boundary layer flow and heat transfer of a nanofluid past a permeable stretching sheet with velocity, thermal and solutal slip boundary conditions. Computers and Fluids 2013, 75, 1-10, https://doi.org/10.1016/j.compfluid.2013.01.014.

8. Naramgari, S.; Sulochana, C. MHD flow over a permeable stretching/ shrinking sheet of a nanofluid with suction/ injection. Alexandria Eng. J. 2016, 55, 819-827, https://doi.org/10.1016/j.aej.2016.02.001.

9. Afify, A. MHD free convective flow and mass transfer over a stretching sheet with chemical reaction. Heat Mass Transfer 2004, 40, 495-500, https://doi.org/10.1007/s00231-003-0486-0.

10. Kechil, S. A.; Hashim, I. Series solution of flow over nonlinearly stretching sheet with chemical reaction and magnetic field. Phys. Lett. A 2008, 372, 2258-2263, https://doi.org/10.1016/j.physleta.2007.11.027.

11. Aziz, A. A similarity solution for laminar thermal boundary layer over a flat plate with convective surface boundary condition. Comm. Nonlinear Sci. Numer. Simul. 2009, 14, 1064-1068, https://doi.org/10.1016/j.cnsns.2008.05.003.

12. Ishak, A. Similarity solutions for flow and heat transfer over a permeable surface with convective boundary condition. Appl. Math. Comput. 2010, 217, 837-842, https://doi.org/10.1016/j.amc.2010.06.026.

13. Salleh, M. Z.; Nazar, R.; Pop, I. Boundary layer flow and heat transfer over a stretching sheet with Newtonian heating. J. Taiwan Instit. Chem. Eng . 2010, 41, 651-655, https://doi.org/10.1016/j.jtice.2010.01.013.

14. Subhashini, S. V.; Samuel, N.; Pop, I. Effects of buoyancy assisting and opposing flows on mixed convection boundary layer flow over a permeable vertical surface. Int. Commun. Heat Mass Trans. 2011, 38, 499-503, https://doi.org/10.1016/j.icheatmasstransfer.2010.12.041.

15. Mohamed, M. K. A.; Salleh, M. Z.; Nazar, R.; Ishak, A. Numerical investigation of stagnation point flow over a stretching sheet with convective boundary conditions. Boundary value Problems 2013, 2013:4, https://doi.org/10.1186/1687-2770-2013-4.

16. Gorsan, T.; Merkin, J. H.; Pop, I. Mixed convection boundary-layer flow on a horizontal flat surface with a convective boundary condition. Meccanica 2013, 48, 2149-2158, https://doi.org/10.1007/s11012-013-9730y. 
17. Chand, G.; Jat, R. N.; Rajotia, D. MHD slip flow over a stretching sheet with convective boundary condition, Acta Technica 2015, 60, 179-191.

18. Mansur, S.; Ishak, A. Unsteady boundary layer flow of a nanofluid over a stretching/shrinking sheet with a convective boundary condition. J. Egyptian Math. Soc. 2016, 24, 650-655, https://doi.org/10.1016/j.joems.2015.11.004.

19. Roy, S.; Anilkumar, D. Unsteady mixed convection from a rotating cone in a rotating fluid due to the combined effects of thermal and mass diffusion. Int. J. Heat Mass Transfer 2004, 47, 1673-1684, https://doi.org/10.1016/j.ijheatmasstransfer.2003.10.028.

20. Siddheshwar, P. G.; Nerolu M., Pažanin I.. Flow and heat transfer in a newtonian nanoliquid due to a curved stretching sheet. Zeitschrift für Naturforschung A. 2017, 72, 833-42, https://doi.org/10.1515/zna-2017-0156.

21. Mallikarjuna, H. B.; Nirmala T., Punith Gowda, R. J. Manghat, R., Varun Kumar, R. S. Two-dimensional Darcy-Forchheimer flow of a dusty hybrid nanofluid over a stretching sheet with viscous dissipation. Heat Transf. Asian Res. 2021, 50, 3934-47, https://doi.org/10.1002/htj.22058.

22. Rajput, G. R.; Jadhav, B. P.; Salunkhe, S. N. Magnetohydrodynamics boundary layer flow and heat transfer in porous medium past an exponentially stretching sheet under the influence of radiation. Heat Transf. Asian Res. 2020, 49, 2906-20, https://doi.org/10.1002/htj.21752.

23. Gajjela, N.; Nandkeolyar, R. Investigating the magnetohydrodynamic flow of a couple stress dusty fluid along a stretching sheet in the presence of viscous dissipation and suction. Heat Transf. Asian Res. 2021, 50, 270924, https://doi.org/10.1002/htj.22001.

24. Megahed, A. M., Reddy.; M. G.; Abbas, W. Modeling of MHD fluid flow over an unsteady stretching sheet with thermal radiation, variable fluid properties and heat flux. Math. Comput. Simul. 2021, 185, 583-593, https://doi.org/10.1016/j.matcom.2021.01.011.

25. Bognár, M.; Raja, M. A.; Sabir, M.T.; Islam, S.; Shah, Z.; Kumam, P.; Alrabaiah, H. Numerical investigation for rotating flow of MHD hybrid nanofluid with thermal radiation over a stretching sheet. Sci. Rep. 2020, 10, 1-5, https://doi.org/10.1038/s41598-020-75254-8.

26. Walelign, T.; Kebede, T.; Haile, E.; Walelgn, A. Analytical study of heat and mass transfer in unsteady MHD radiant flow of Williamson nanofluid over stretching sheet with heat generation and chemical reaction. Heat Transf. Asian Res. 2020, 49, 4246-63, https://doi.org/10.1002/htj.21825.

27. Muthukumaran, C.; Bathrinathan, K. Mathematical modeling of mixed convection boundary layer flows over a stretching sheet with viscous dissipation in presence of suction and injection. Symmetry. 2020,12, 1754, https://doi.org/10.3390/sym12111754.

28. Qasim, M.; Riaz, N., Lu, D.; Afridi, M.I. Mixed convection flow over a stretching sheet of variable thickness: Analytical and numerical solutions of self-similar equations. Heat Transf. Asian Res. 2020, 49, 3882-99, https://doi.org/10.1002/htj.21813.

29. Ghatani, Y.; Roshan, T.; Maity, S. Unsteady thin Casson-nanoliquid film flow over a porous stretching sheet. Eur. Phys. J.: Spec. Top. 2021, 1-3, https://doi.org/10.1140/epjs/s11734-021-00055-7.

30. Mahabaleshwar, U. S.; Sneha, K. N.; Huang, H. N. An effect of MHD and radiation on CNTS-Water based nanofluid due to a stretching sheet in a Newtonian fluid. Case Stud. Therm. Eng. 2021, 101462 https://doi.org/10.1016/j.csite.2021.101462.

31. Kumar, M. Study of differential transform technique for transient hydromagnetic Jeffrey fluid flow from a stretching sheet. Nonlinear Eng. 2020, 9, 145-155. https://doi.org/10.1515/nleng-2020-0004.

32. Naganthran, K.; Hashim, I.; Nazar, R. Non-uniqueness solutions for the thin Carreau film flow and heat transfer over an unsteady stretching sheet. Int. Commun. Heat Mass Transf. 2020, 117, 104776. https://doi.org/10.1016/j.icheatmasstransfer.2020.104776.

33. Ilyas, H.; Ahmad, I.; Raja, M. A. Z.; Shoaib, M. A novel design of Gaussian Wavelets for rotational hybrid nanofluidic flow over a stretching sheet involving thermal radiation. Int. Commun. Heat Mass Transf. 2021, 123, 105196. 0.1016/j.icheatmasstransfer.2021.105196.

34. Khan, M. N.; Nadeem, S. A comparative study between linear and exponential stretching sheet with double stratification of a rotating Maxwell nanofluid flow. Surf. and Interfaces. 2021, 22, 100886 https://doi.org/10.1016/j.surfin.2020.100886.

35. Bognár, G.; Hriczó, K. Ferrofluid flow in magnetic field above stretching sheet with suction and injection. Math. Model. Anal. 2020, 25, 461-472 https://doi.org/10.3846/mma.2020.10837.

36. Das, M.; Mahanta, G.; Shaw, S. Heat and mass transfer effect on an unsteady MHD radiative chemically reactive Casson fluid over a stretching sheet in porous medium. Heat Transf. Asian Res. 2020, 49, 43504369. https://doi.org/10.1002/htj.21830. 